\title{
WHATSAPP: UM VIÉS ONLINE COMO ESTRATÉGIA DIDÁTICA NA FORMAÇÃO PROFISSIONAL DE DOCENTES
}

\author{
WHATSAPP: AN ONLINE BIAS AS A TEACHING STRATEGY \\ IN TEACHER TRAINING
}

\section{WHATSAPP: UN BIAS LÍNEA COMO ESTRATEGIA EN LA ENSEÑANZA DE FORMACIÓN DE PROFESORE}

Vera Lucia Pontes dos Santos

Jasete Maria da Silva Pereira

\section{Luís Paulo Leopoldo Mercado}

RESUMO: As Tecnologias Digitais da Informação e Comunicação (TDICs) despontam no cenário educativo como nova nomenclatura para compor mídias analógicas e digitais presentes na sociedade. Isso gera impactos no ensinoaprendizagem, impulsionando os docentes a atualizações profissionais. As TDICs que surgiram para comunicar e transmitir informações representam amplas possibilidades, inclusive integração às práticas educacionais. $O$ Whatsapp foi experimentado com estudantes de Pedagogia visando ao uso como estratégia didática na formação inicial de docentes. A pesquisa pairou nesta incerteza: como estratégias didáticas integradas às TDICs podem favorecer a formação de docentes? Nesse contexto, dados qualitativos da pesquisa evidenciaram vantagens e desvantagens do aplicativo.

PALAVRAS-CHAVE: Estratégia didática. Formação de docentes. Whatsapp.

\begin{abstract}
The Digital Information Technologies and Communication (TDIC) emerge in the educational setting as a new nomenclature to compose analog and digital media in society. This generates impacts on teaching and learning boosting teachers to professional updates. The TDIC that appeared to communicate and transmit information representing broad possibilities, including integration to educational practices. Whatsapp tested with students of pedagogy aiming to use as a teaching strategy in initial teacher education. Search hovered this uncertainty: how teaching strategies integrated with TDIC may favor the formation of teachers? In this context, qualitative research data showed advantages and disadvantages of the application.
\end{abstract}

KEYWORDS: Training Strategy. Training for teachers. Whatsapp.

RESUMEN: Información y Comunicación Digital Technologies ( TDIC ) surgen en el entorno educativo como nueva nomenclatura para componer analógica y medios digitales presentes en la sociedad. Esto genera impactos sobre la enseñanza y el aprendizaje de los profesores que impulsan a las actualizaciones profesionales. El TDIC que salió para comunicar y transmitir información representa grandes oportunidades, incluyendo la integración de las prácticas educativas. El Whatsapp se experimentó con los estudiantes de Pedagogía con el objetivo de utilizar como estrategia de enseñanza en la formación inicial del profesorado. La investigación se cernía esta incertidumbre: cómo las estrategias de enseñanza integradas con TDIC puede favorecer la formación de los profesores? justificado, espaçamento simples.

PALABRAS CLAVE: La enseñanza de la estrategia. La formación del profesorado. Whatsapp.

\footnotetext{
${ }^{1}$ Mestranda em Educação e licenciada em Pedagogia pela Universidade Federal de Alagoas - UFAL, Maceió, AL Brasil. E-mail: vera.lucia@prograd.ufal.br.

${ }^{2}$ Mestra em Educação pela Universidade Federal de Alagoas - UFAL, Maceió, AL - Brasil. Professora do Instituto Federal de Alagoas, Maceió, AL - Brasil. E-mail: jaspetur@gmail.com.

${ }^{3}$ Doutor em Educação pela Pontifícia Universidade Católica de São Paulo. Professor Associado do Centro de Educação Universidade Federal de Alagoas - UFAL, Maceió, AL - Brasil. E-mail: luispaulomercado@gmail.com.

Recebido em: 25/06/2015 - Aprovado em: 07/03/2016.
} 


\section{INTRODUÇÃO}

A sociedade do conhecimento é resultado do avanço tecnológico ocorrido a partir da década de 1990, e vem exigindo uma nova postura do profissional ligado diretamente ao segmento educacional no que tange ao processo de ensino-aprendizagem. Dessa forma, acredita-se ser essencial pensar a educação com olhar voltado para outras práticas pedagógicas, amparadas em elementos midiáticos que possibilitem o uso fluído de imagens, sons, movimentos, links e hiperlinks.

Nesse cenário, as TDICs são uma nova terminologia que surge para dar conta dessa multiplicidade de mídias analógicas e digitais presentes nos espaços educacionais, profissionais, econômicos e sociais. Marinho e Lobato (2008) referenciam as TDICs como tecnologias que têm o computador e a internet como ferramentas fundamentais que se distinguem das tecnologias de informação e comunicação (TICs) pela presença do dispositivo 'digital'.

Defende-se que a formação do docente, para coexistir com as demandas didático-pedagógicas desse novo tempo, exige novas competências, além do domínio de sua área de formação e atuação. Dentre elas, o domínio das técnicas e procedimentos didáticos inerentes ao ensino-aprendizagem, a capacidade de interação e reflexão constantes com seus pares, o melhor conhecimento sobre a docência online, sem perder de vista a apropriação e a integração das TDICs às práticas educativas.

Cabe aos profissionais da educação, atualizar-se a esse respeito, uma vez que não se pode negar a ascensão dos recursos tecnológicos e os impactos destes nas formas de ensinar e aprender. Neste sentido, Barbosa et al. (2014, p. 3642) defendem:

(...) antes, para exercer esta atividade, era necessário ter apenas conhecimentos específicos sobre a área a qual iria lecionar, contudo, atualmente isso vem se modificando: necessita-se de professores que além dos conhecimentos específicos de sua área dominem técnicas e procedimentos de ensino.

Com uma visão analítica dos pensamentos verbalizados pelos autores, observa-se a urgência que deve ser dada à inserção de novas estratégias didáticas ao ensino, para que o docente possa desfrutar das inúmeras possibilidades permitidas pelas TDICs. De acordo com Valente (2011), além do computador e da internet, as informações/comunicações se manifestam por meio de instrumentos físicos, quais sejam: imprensa, imagens, rádio, vídeos, televisão, DVD, notebook, laptop, tablets, smartphone que, conectados à internet, disponibilizam ferramentas como Moodle, Blogs, Facebook, Twitter, Fóruns, Jogos Digitais, Apps, Whatsapp, etc.

Inicialmente, esses aparatos tecnológicos surgiram com a finalidade de comunicar e transmitir informações, mas, hoje, representam possibilidades múltiplas. Uma delas é a viabilidade de integrálos às práticas educacionais como elementos potencializadores dos processos formativos, quer sejam acadêmicos, quer sejam profissionais (FRAGOSO et al., 2012; SANTOS e ROSSINI, 2013; IZZO et al., 2010; SILVA, 2012).

Espera-se que as TDICs e seu uso significativo e inovador possam efetivamente ser integradas ao currículo e ao exercício do docente. Nesse sentido, Almeida e Moran (2005) e Valente 
(2011) defendem que muito mais importante do que trazer as mídias para dentro da sala de aula, é mobilizá-las em favor do ensino-aprendizagem, com vistas à apropriação e/ou construção de saberes/fazeres, uma vez que esses recursos podem fortalecer o ensino quando revestidos de boa intervenção didática.

Nessa perspectiva, durante a oferta da disciplina Metodologia do Ensino Superior com TICs do Mestrado e Doutorado, de uma Instituição Federal de Ensino Superior (IFES), os pesquisadores sentiram-se motivadas a utilizar a interface do Whatsapp como rede social, no intuito de descobrir o efeito desse aplicativo como estratégia didática na formação profissional de docentes.

Essa motivação deu-se a partir do conhecimento prévio que os pesquisadores tinham da ferramenta como uso pessoal. A fim de testar as potencialidades do recurso midiático, no campo acadêmico, como estratégia de ensino superior, escolheram estudantes de Pedagogia, por pertencerem a um curso de formação de docentes.

Ao pensar a formação docente para atuar no mundo globalizado, os pesquisadores concordam que:

(...) A atividade docente não é exercida sobre um objeto, sobre um fenômeno a ser conhecido ou uma obra a ser produzida. Ela é realizada concretamente numa rede de interações com outras pessoas, num contexto onde o elemento humano é determinante e onde estão presentes símbolos, valores, sentimentos, atitudes, que são passíveis de interpretação e decisão que possuem (TARDIFF, 2010, p. 49).

Em se tratando do exercício docente, o discurso dos pesquisadores incorre na concepção do autor, tendo em vista entenderem que a práxis de muitos educadores advém de valores socioculturais, adquiridos em experiências vividas ao longo de sua trajetória pessoal, acadêmica e profissional.

Desse modo, a pesquisa foi mobilizada para a utilização do Whatsapp, como viés online, para refletir sobre a integração das TDICs às aulas de formação de docentes. Tal pesquisa amparou-se na pressuposição de que o experimento com estudantes - futuros pedagogos - apresentaria elementos determinantes para avaliação do uso pedagógico do Whatsapp no processo de formação de docentes, a partir das interações conceptuais dos estudantes. Imbuídos nesse contexto, a proposta do trabalho investigativo pairou na seguinte incerteza: como novas estratégias didáticas integradas às TDICs podem favorecer a formação inicial de docentes?

Diante do exposto, este artigo objetivou avaliar as potencialidades didáticas do Whastapp na formação de docentes, com ênfase no uso do áudio e da mensagem escrita. Para isso, os pesquisadores contaram com a anuência de teóricos que dialogam sobre: TDICs (SILVA, 2012; VALENTE, 2011; ALMEIDA e MORAN, 2005; CASTELLS, 2007), Formação de docentes (BARBOSA et al., 2014; TARDIFF, 2010; RAMOS, 2010) e Rede Social (LENHART et al., 2007, ALSALEEM, 2013), entre outros. 
Nessa direção, abordar-se-á a formação de docentes, buscando constatar o que muda no processo educativo a partir da integração desses aparatos tecnológicos. Evidencia-se, portanto, a importância das redes sociais, em destaque o Whatsapp, como estratégia didática na formação de docentes.

\section{CURRÍCULO, FORMAÇÃO DE DOCENTES E TDICS}

A expansão das mídias digitais e a incontestável presença desses aparatos tecnológicos nos espaços acadêmicos são indícios de que o currículo e os métodos tradicionais não atendem mais as atuais exigências educacionais e societárias. Esses desafios são latentes e tendem a impulsionar os docentes à busca de metodologias que integrem as TDICs. O que se busca é a inovação das aulas para atender as expectativas dos estudantes e a promoção de uma formação necessária à convivência em uma 'sociedade em rede', ainda que poucos docentes estejam abertos a mudanças (CASTELLS, 2007).

Essa sociedade conectada em 'nós', que se integram e se multiplicam, delineia-se mais fluída, volátil e ascende em uma proporção ilimitada e veloz, o que possibilita uma articulação social e disseminadora da comunicação entre as pessoas. Sobre essa cultura digital, Castells (2007, p. 24) pontua que "devemos localizar este processo de transformação tecnológica revolucionária no contexto social em que ele ocorre e pelo qual está sendo moldado". Ao pensar sobre essa concepção do autor, considera-se pertinente e urgente a ideia de integrar as ferramentas online disponíveis, tais como o Facebook, o Skype, o Qr Code, o Blog, o Whatsapp, dentre outros recursos midiáticos, ao currículo e ao dia a dia dos cursos de formação de docentes (VALENTE, 2011).

Esses pressupostos levam-nos a alguns questionamentos: que saberes, competências e habilidades relativas às TDICs estão sendo desenvolvidos nos cursos de formação de docentes? O currículo das licenciaturas tem contemplado disciplinas sobre a utilização pedagógica das TDICs com cargas horárias suficientes e materiais tecnológicos adequados? Os futuros docentes estão preparados para integrar as TDICs às suas práticas pedagógicas?

Buscou-se no Projeto Político-pedagógico do Curso (PPC) de Pedagogia de uma IFES, referências para analisar essas questões. Criado em 1955 e reconhecido em 1961, pelo Decreto Federal n. 49.849, o referido curso é ofertado na modalidade presencial e tem carga horária total de 3.500 horas, podendo ser integralizado em um período entre quatro e sete anos, compondo uma das licenciaturas, que são cursos de formação de docentes. Conforme o que consta no respectivo PPC, apresenta-se o perfil do egresso:

(...) profissional que conceba o fenômeno educativo no processo histórico, dinâmico e diversificado, respondendo criticamente aos desafios que a sociedade lhe coloca; que atue de forma reflexiva, crítica, cooperativa, com ética e conhecimento fundamentado, com habilidades para levantar problemas e, principalmente propor alternativas de intervenção para a educação básica no Brasil; que exerça a capacidade de liderança e de busca do conhecimento; que produza conhecimentos como docente/pesquisador/gestor de processos pedagógicos que envolvam crianças, jovens e/ou adultos, em instituições escolares e não escolares (UFAL, 2006, p. 03). 
Com base no perfil, o licenciado em Pedagogia, dentre outros campos de atuação, poderá atuar em escolas, sistemas educacionais e outras organizações, estando apto a exercer funções de magistério na educação infantil e nos anos iniciais do Ensino Fundamental; nas disciplinas pedagógicas dos cursos de Ensino Médio na modalidade normal; na Educação Profissional na área de serviços e apoio escolar, tendo como base a docência (UFAL, 2006, p. 3).

Como gestor de processos pedagógicos que envolvam crianças, jovens e adultos em instituições escolares, um dos saberes e habilidades que precisam ser desenvolvidos na formação do profissional de Pedagogia é a "capacidade de desenvolver metodologias e materiais pedagógicos adequados à utilização das tecnologias da informação e da comunicação nas práticas educativas" (UFAL, 2006, p. 26).

Tendo por referência essas concepções, a estrutura do referido curso de Pedagogia tem seu desdobramento em três núcleos de estudos: a) Núcleo de estudos básicos (780 h); b) Núcleo de aprofundamento e diversificação de estudos (1.680 h) e; c) Núcleo de estudos integradores (680 h). Ao analisar o desenho curricular do turno diurno, notou-se que as TDICs são contempladas como componentes curriculares apenas no primeiro período do curso, que compreende o Núcleo de Estudos Básicos, com carga horária de 80 horas, conforme quadro abaixo:

QUADRO 1 - Matriz Curricular do Núcleo de Estudos Básicos - Curso de Pedagogia

\begin{tabular}{|c|c|c|c|c|c|}
\hline \multicolumn{6}{|c|}{$1^{0}$ Período } \\
\hline \multirow[t]{2}{*}{ Eixo } & \multirow[t]{2}{*}{ Módulo } & \multirow{2}{*}{ Saberes/Componentes Curriculares } & \multicolumn{3}{|c|}{ Carga Horária } \\
\hline & & & $\mathbf{T}$ & $\mathbf{P}$ & Total \\
\hline \multirow{5}{*}{ Contextual } & \multirow{2}{*}{$\begin{array}{l}\text { Educação: Natureza e } \\
\text { Sentido }\end{array}$} & Fundamentos Filosóficos da Educação & 70 & 10 & 80 \\
\hline & & $\begin{array}{l}\text { Fundamentos Históricos da Educação e } \\
\text { da Pedagogia }\end{array}$ & 70 & 10 & 80 \\
\hline & $\begin{array}{l}\text { Trabalho, Educação e } \\
\text { Profissão }\end{array}$ & Profissão Docente & 50 & 10 & 60 \\
\hline & \multirow{2}{*}{$\begin{array}{l}\text { Educação, } \\
\text { Conhecimento e } \\
\text { Informação }\end{array}$} & Organização do Trabalho Acadêmico & 40 & 20 & 60 \\
\hline & & $\begin{array}{l}\text { Educação e Novas Tecnologias da } \\
\text { Informação e da Comunicação }\end{array}$ & 60 & 20 & 80 \\
\hline Articulador & $\begin{array}{l}\text { Mergulhando na } \\
\text { Prática Pedagógica }\end{array}$ & Projetos Integradores I & 20 & 20 & 40 \\
\hline \multicolumn{3}{|l|}{ Subtotal } & 310 & 90 & 400 \\
\hline
\end{tabular}

Fonte: UFAL, 2006.

Observa-se no Quadro 1 que ‘Educação, Conhecimento e Informação' é um dos módulos que compõem o Eixo Contextual e é nesse módulo que se vincula a disciplina 'Educação e Novas Tecnologias da Informação e da Comunicação'. Ao observar a matriz curricular em todos os períodos, o que se nota é que esse módulo repete-se no primeiro e segundo períodos do curso, com carga horária total de 260 horas, da qual aproximadamente $30 \%$ são reservadas ao trabalho com as TDICs. O restante distribui-se em disciplinas como 'Organização do Trabalho Acadêmico', 'Fundamentos Psicopedagógicos da Educação' e 'Leitura e produção textual em língua portuguesa'.

O PPC não dá conta de mostrar o que subjaz o currículo, ou seja, se as TDICs são incorporadas à práxis dos docentes formadores desses profissionais e se os mesmos participam de \begin{tabular}{l|l|l|l|l|l|l} 
(C) ETD - Educ. Temat. Digit. & Campinas, SP & v.18 & n.1 & p. 104-121 & jan./abr.2016 & ISSN 1676-2592
\end{tabular} 
formação continuada, que é um possível canal de reflexão sobre a própria atividade e de apropriação de inovações curriculares, metodológicas e tecnológicas. Caberão, portanto, outras investigações que possibilitem adentrar no universo da docência universitária, em forma prática.

Há amplas possibilidades para se trabalhar com as TDICs, como objeto e prática, o que convém recomendar aos que exercem e/ou pretendem exercer a docência uma análise e reflexão constantes a respeito, seja no meio profissional, seja no meio acadêmico. Questões que irrompam com o paradigmatismo tradicional e que concorram para a adesão e uso de novas metodologias de ensino devem pautar essas análises, a fim de que a educação caminhe pari passu com a sociedade do conhecimento (CASTELLS, 2007).

Para tanto, deve-se considerar que a formação profissional do docente precisa estar continuamente moldada a outros feitios e auxiliada por conexões em rede. Na acepção de Peters (2008, p. 184), quando a docência configura-se em "espaços virtuais, a aprendizagem se dá de maneira associativa, aleatória, descentralizada, fluída e opaca, não localizada e distributiva, e o currículo é aberto".

Em contrapartida, há uma tendência equivocada de inovação metodológica baseada no uso das TDICs nos moldes didáticos tradicionais, fundamentados na crença de que, quem domina a prática, consequentemente sabe ensinar (MASETTO, 1998). O uso pedagógico das TDICs nas Instituições de Ensino Superior (IES) pelos docentes pode contribuir para a superação desse mero domínio técnico e operativo das ferramentas (KARSENTI et al., 2008; BASTOS, 2010; VALENTE, 1999). Segundo Almeida e Moran (2005, p. 2), esse cenário reforça a necessidade de "desenvolver processos formativos que privilegiem a formação em serviço, com base na reflexão sobre a própria prática”.

Do mesmo modo, acredita-se que a implementação de percursos curriculares flexíveis no formato da não linearidade, com disciplinas e práticas voltadas diretamente para a formação de docentes, seja uma preocupação dos gestores dos cursos de licenciatura das IES, o que sinaliza perspectivas de mudanças. Por outro lado, a Portaria MEC n. ${ }^{\circ} 4.059 / 2004$ estabelece que 20\% da carga horária dos cursos superiores poderão ser cumpridas na modalidade semipresencial, o que tem contribuído para a inserção de disciplinas voltadas para o ensino na modalidade a distância. Mas, por ser um formato ainda recente, os docentes que militam nessa área demonstram certo grau de timidez e insegurança para mediar conhecimentos, em parceria com os recursos tecnológicos, isto porque não foram qualificados para lidar com essa base didática.

É urgente a formação continuada dos docentes que atuam nas IES, pois enquanto as aulas são auxiliadas pela lousa escolar e, muitas vezes, pelo PowerPoint, fundadas em uma abordagem expositiva, evidencia-se a ocupação das salas de aula por 'nativos digitais'. Segundo Palfrey e Gasser (2011, p. 14), “os jovens que estão se tornando alunos universitários e ingressando na força de trabalho, embora vivendo grande parte de suas vidas online, são diferentes de nós em muitas dimensões”. Essa nova geração é denominada de nativos digitais porque não tem que reaprender 
nada para viver suas vidas de imersão digital. "Eles começaram a aprender na linguagem digital; só conhece o mundo digital" (Idem).

Essa falta de sintonia tecnológica/didática entre "quem ensina" e "quem aprende" pode ser prejudicial ao processo educativo, uma vez que há uma mudança clara e generalizada nas formas de comunicação e interação entre as pessoas e na capacidade multimidiática das TDICs (COLL e MONEREO, 2010), e isto precisa refletir nos espaços educacionais.

Nessa direção, as IES devem investir em programas de formação continuada no sentido de promover eventos formativos fundados nos saberes/fazeres em docência universitária para que, efetivamente, esse processo reflita mudanças pedagógicas e tecnológicas (ZABALZA, 2004; RAMOS, 2010) na formação profissional de docentes. Na visão de Ramos (2010, p. 89) trata-se de criar um "espaço que possibilite contribuir para desconstruir a concepção de docente como profissional de um saber e fornecer elementos estruturantes para que os docentes se compreendam e se assumam como profissionais de ensino".

Diante desse cenário, surgiu o interesse destes pesquisadores em investigar se o uso do Whatsapp pode ser concebido como estratégia de ensino na formação de docentes que vão atuar na educação básica, a partir da descrição e análise de uma experiência vivenciada por três discentes de um curso de Pedagogia.

\section{WHATSAPP: UMA ESTRATÉgIA POTENCIAL NA FORMAÇÃO PROFISSIONAL DE DOCENTES?}

Com a expansão das mídias digitais e da internet, os discentes passaram a ter acesso a diversos recursos por intermédio do e-mail e de outros meios de comunicação, como sites de redes sociais e aplicativos para telefones inteligentes (FOGG, 2010). Com isso, tecnologias de mensagens, a exemplo do Whatsapp, conseguiram um lugar crescente nos meios sociais, sendo amplamente utilizadas entre discentes de graduação (LENHART et. al., 2007).

O foco deste artigo paira na ferramenta Whatsapp Messenger ${ }^{4}$, que segundo Alsaleem (2013), dentre os aplicativos emergentes, é um dos mais populares, estando disponível para Android, iPhone, Windows Phone, BlackBerry e Nokia. É um aplicativo de mensagens multiplataforma (FERNANDES et al., 2012) que permite a troca de mensagens gratuitas. Como o Whatsapp Messenger utiliza o mesmo plano de dados de internet do usuário para e-mails e navegação, só é necessário um número de celular para se identificar e ter acesso ao serviço (ALSALEEM, 2013).

É crescente o avanço dos recursos tecnológicos para mediar conhecimentos, por meio de ferramentas disponíveis na internet. O docente universitário ao subestimar essa realidade, pode estar ignorando sua inserção na 'sociedade em rede' e restringindo a formação de seus estudantes. O uso pedagógico das TDICs emerge como um desafio em todos os níveis educacionais, principalmente na

4 Informações sobre natureza e funcionalidade do Whatsapp foram produzidas a partir do site: http://www.whatsapp.com. Acesso em 7 jul. 2014. 
educação superior, seja pela fragmentação do currículo dos cursos de graduação, seja pela frágil formação pedagógica dos docentes ao exercício qualitativo (SACRISTÁN, 1995; CUNHA, 2007; MELO, 2008; RAMOS, 2010).

Ao analisar que a telefonia móvel tem possibilitado a integração comunicativa entre todos os espaços sociais, investigamos se o Whatsapp também teria utilidade no espaço universitário como estratégia pedagógica. Segundo Barbosa et al. (2014), a origem histórica da universidade é legitimada como lócus do conhecimento, o que de certa forma leva a crer que o espaço acadêmico deve acompanhar as mudanças que ocorrem no mundo globalizado, procurando quebrantar os obstáculos que promovem à ascensão do saber.

Nessa perspectiva foi conduzido o trabalho de pesquisa com estudantes do quarto e quinto períodos do Curso de Pedagogia de uma IFES, apoiada em análise prévia feita à matriz curricular do curso. Detectou-se que nesses períodos os estudantes já tinham cumprido os créditos referentes ao componente curricular 'Educação e Novas Tecnologias da Informação e Comunicação'. O objetivo da pesquisa foi analisar as potencialidades didáticas do Whatsapp na formação profissional de docentes.

A partir do consentimento dos sujeitos da pesquisa, realizaram-se os procedimentos de formalização do experimento por meio dos quais se explicou a natureza, os objetivos e a metodologia para a produção dos dados.

A pesquisa teve início no dia 17 de maio de 2014, quando foi criado o grupo intitulado 'Potencialidades do Whatsapp' e se estendeu até o dia 31 daquele mês, perfazendo um total de 14 dias de interatividade online. Na divulgação dos dados produzidos, buscou-se preservar a identidade dos participantes, substituindo os nomes por 'pesquisador' e 'estudante', acompanhado de ordem numérica. Assim, tem-se 'Pesquisador 1', 'Pesquisador 2', 'Estudante 1', 'Estudante 2', e assim sucessivamente.

Os pesquisadores cuidaram para que o ambiente no qual se configurou a pesquisa possibilitasse um diálogo qualitativo e focalizado que ganhou força e dimensão a partir da primeira provocação compartilhada no grupo. O primeiro ponto de discussão foi um fragmento de texto sobre formação de docentes para uso das TICs. Nesse sentido, as pesquisadoras acreditaram que o diálogo seria mais bem direcionado se partisse de um tema disparador que embasasse a produção dos dados da pesquisa. O Quadro 2 exibe o tema disparador, o qual foi resgatado da conversa do grupo pelo link do Whatsapp com o Gmail: 
QUADRO 2 - Tema disparador: Formação de professores para uso das Tecnologias

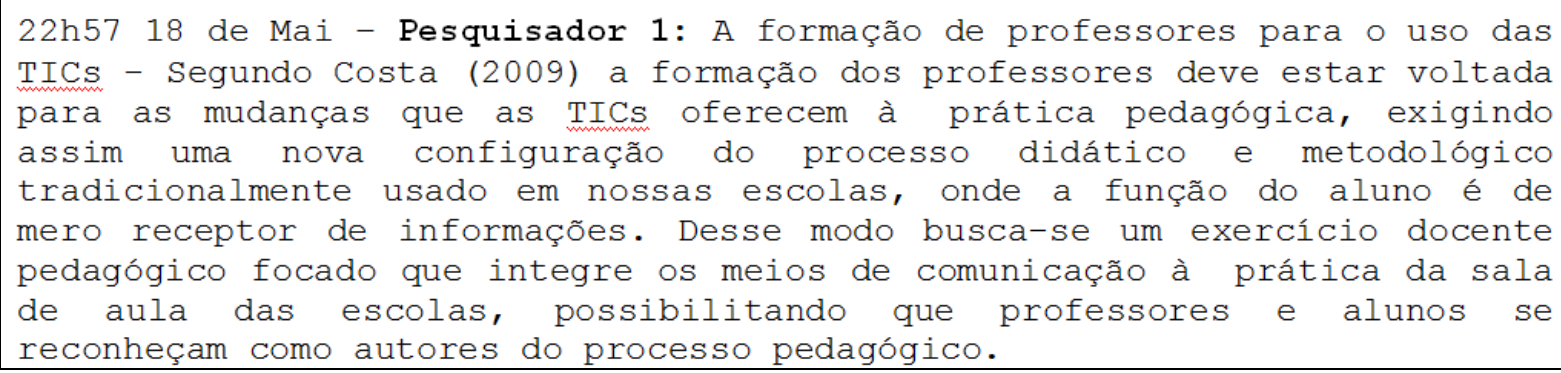

Fonte: Costa, 2009, p. 135/136.

A entrevista foi realizada por meio da comunicação síncrona e assíncrona, tendo em vista a dificuldade de reunir todos em um mesmo horário, em razão da indisponibilidade de tempo dos participantes. Dessa forma, esse movimento foi acontecendo, possibilitando que as pesquisadoras avaliassem se o diálogo reflexivo online em aparelhos móveis efetivamente configurava-se como um meio potencial metodológico na formação dos futuros docentes.

Esse exercício permitiu a constatação das propriedades e das possibilidades do Whatsapp quando usado por grupos que perseguem um objetivo pedagógico comum. Entre as possibilidades de conversação, verificou-se que as mediações comunicativas podem ser realizadas pelas interfaces áudio e mensagem escrita. Sobre esses elementos destacam-se depoimentos dos sujeitos de pesquisa ao serem perguntados se gostaram de participar da experiência com o Whatsapp e por que preferiram responder usando o áudio e/ou a mensagem escrita:

Estudante 1 - Sim gostei. [...] foi bastante cômodo participar de uma discussão tão inovadora num espaço que muitos acreditam não dar certo, [...] principalmente para provar que este meio pode ser muito bem aproveitado, vai depender das pessoas que o utilizam. Eu preferi mandar minhas respostas por escrito por comodidade em respondê-las em qualquer lugar de maneira mais discreta (27/05/2013, às 23h24).

Estudante 2 - Gostei muito de ter participado dessa pesquisa, [...] não tive como usar o áudio para responder as questões por conta de um problema no celular, mais as TIC estão vulnerável a esses tipos de contratempos, por isso usei a escrita para expressar minha opinião sobre os questionamentos, [...] usaria as duas formas sem nenhum problema (29/05/2014, às 18h49).

Estudante 3 - Eu gostei de participar da entrevista via Wathsapp, pois essa experiência me deu mais uma ferramenta para trabalhar em sala de aula. [...] percebi a partir da pesquisa que ele pode ser utilizado, também, como uma ferramenta direta de aprendizado. [...] preferi utilizar o áudio, para respostas muito longas, a escrita torna-se cansativa (31/05/2014, às 12h05).

O que se depreende das falas dos estudantes é que os futuros docentes convergem em um mesmo pensamento: a compreensão da importância das TDICs e da apropriação do aplicativo Whatsapp como mais um espaço online inovador para a concepção do ensino-aprendizagem, que pode ser explorado por docentes e estudantes universitários, em que se tem tanto no áudio quanto na mensagem escrita mecanismos facilitadores da interação, por causa das possibilidades de comunicação síncrona e assíncrona. 
A pesquisa foi direcionada na intenção de analisar três pontos principais: a) o que pensam os estudantes sobre o uso pedagógico das TDICs; b) que expectativas estão sendo geradas na formação profissional do docente para lidar com as TDICs; c) que práticas são e podem ser adotadas em sala de aula utilizando os recursos midiáticos.

Em se tratando desses pressupostos, de acordo com os dados produzidos na experiência com os estudantes de Pedagogia, houve uma ideia clara da importância do uso pedagógico das TDICs na visão dos estudantes. A partir da interpretação desses dados e considerando os três pontos de análise, destacamos algumas percepções dos estudantes.

a) Pensamento dos discentes sobre o uso pedagógico das TDICs:

- as TDICs integram recursos educativos digitais que podem ser usados nas diversas áreas de conhecimento;

- as TIDCs mudaram a forma de fazer educação e consequentemente as práticas dentro do contexto sala de aula;

- as TDICs podem ser usadas concomitantemente às aulas e também no apoio de atividades de aprofundamento desde que se faça bom uso delas;

- as TDICs consistem em uma perspectiva de mudança na forma de interação estudante/docente e pode aumentar o interesse do discente à aula;

- o uso das TDICs na sala de aula pode potencializar as práticas docentes;

- o ponto negativo das TDICs é a vulnerabilidade ocasionada por barreiras técnicas.

b) Expectativas que estão sendo geradas na formação profissional do docente para lidar com as TDICs:

- o trabalho educativo descontextualizado do mundo dos estudantes pode ocasionar desinteresse e monotonia na sala de aula;

- os cursos de Pedagogia geralmente ofertam uma única disciplina que aborda a integração das TDICs;

- os futuros docentes demonstram não estar preparados para trabalhar com as TDICs;

- o conhecimento e a prática que alguns estudantes têm são oriundos das experiências pessoais com uso de mídias socais e com a internet;

- a realização de práticas inovadoras na IES pode acrescentar nas práticas dos futuros docentes, que refletirá na qualidade da educação básica;

- a abordagem didática das TDICs exige inovação, atualização e competência;

- a atualização contínua em inovações pedagógicas e tecnológicas pode romper com a prática estritamente tradicional;

- os docentes são desafiados a encontrar novas metodologias de ensino para atender as novas situações que são colocadas diante deles.

c) Práticas que são e podem ser adotadas em sala de aula utilizando os recursos midiáticos:

- a internet possibilita rapidez e produtividade para se informar e se comunicar de forma síncrona e assíncrona;

- as redes sociais constituem espaços de interação, avaliação de aquisição de conhecimentos; 
- a partir das ferramentas disponíveis na internet, os docentes podem criar grupos para as suas disciplinas, o que facilitaria a troca de experiências e a solução de dúvidas sobre as aulas;

- o Facebook é um espaço que possibilita a criação de grupos, de páginas e de perfis;

- o uso do blog como portfólio online de uma disciplina pode representar um meio interativo e colaborativo entre docente, conteúdo e estudante;

- o Whatsapp representa um dos novos recursos midiáticos que podem ser utilizados para fins acadêmicos e didáticos.

As questões analisadas concentraram percepções e expectativas dos estudantes com relação ao uso pedagógico das TDICs nos cursos superiores, em especial nos cursos de licenciaturas, que habilitam profissionais para o ensino na educação básica. Os discursos dos estudantes apontam para uma visão crítica da própria formação, no que tange às condições didáticas e tecnológicas em que a formação se materializa. Afora algumas supressões acessórias, indicadas pelos colchetes, as transcrições a seguir enfatizam o que pensam os futuros docentes acerca do uso pedagógico das novas tecnologias e a formação de seus docentes:

Estudante 1 - O docente [...] tem que estar sempre se atualizando com as novidades que vão aparecendo, principalmente quando se trata de tecnologias. [...] a escola é um espaço que sofre [...] influências externas, a mesma junto aos docentes tem que saber utilizar e tirar proveito dessa nova ferramenta de maneira educativa [...], pois o trabalho escolar estaria totalmente descontextualizado com o mundo de seus discentes [...] (18/05/2014).

Estudante 2 - [...] os docentes são desafiados a encontrar novas metodologias de ensino para atender às novas situações que são colocadas diante deles, [...] as TIC tem seus pontos positivos e negativos e muitos docentes tem restrição em utilizá-las. Mas eu acredito que uma escola tecnologicamente equipada com o material necessário para o docente dá sua aula, seja caminho para a aproximação do docente com o aluno e melhoria do ensino e aprendizagem, [...] principalmente nas escolas públicas (20/05/2014).

Estudante 3 - [...] as TIC mudaram a forma de fazer educação e mudaram as formas de mudar as práticas educacionais dentro contexto da sala de aula. Hoje em dia é praticamente [...] inviável o docente pensar a aula utilizando basicamente o quadro de giz. [...] pensando numa perspectiva de mudança, de interação do aluno com o docente e até do aumento de interesse do aluno à aula, [...] o uso das TIC é muito válido, não somente das tecnologias dentro da sala de aula, mas, o uso das tecnologias extra sala de aula, como uso das mídias sociais e dos blogs, [...] o que facilitaria a compreensão de alguns temas que são difíceis de se tratar dentro da sala de aula. [...] então eu considero e acho válido e muito interessante o uso das TIC na sala de aula e espero que os docentes tragam cada vez mais as tecnologias para dentro da sala de aula porque isto potencializa as práticas docentes (19/05/2014).

As citações dos estudantes corroboram que é urgente que as instituições educacionais busquem acompanhar as mudanças que ocorrem no meio social. Uma IES tecnologicamente equipada pode ser caminho para a melhoria do ensino e aprendizagem, mas nem sempre dispõem de computadores eficientes e de internet de qualidade. Além da desestrutura tecnológica, o despreparo do docente para o ensino mediado pelas TDICs é outro fator que prejudica a integração efetiva destas à educação. Os laboratórios de informática acabam sendo pouco utilizados por estudantes e docentes para fins pedagógicos. 


\section{PERCURSO METOdológico DA PESQUiSA: DA PRODUÇÃo À ANÁLISE DOS DADOS}

Tendo em vista a aceleração tecnológica, a comunicação amplia-se de tal forma que possibilita a abertura de novos horizontes em diversas áreas do conhecimento, inclusive na educação. Nesta perspectiva abordamos os procedimentos metodológicos que permearam este trabalho balizado em estudos qualitativos conforme teoriza Creswell (2007, p. 101) ao afirmar que, nesse tipo de pesquisa, "o objetivo estabelece os propósitos, a intenção e a ideia principal de uma proposta ou de um estudo".

Este trabalho de pesquisa caminhou na direção da análise acerca das vantagens e desvantagens do Whatsapp como recurso metodológico no ensino superior. O diálogo entre os sujeitos da pesquisa suscitou dúvidas, questionamentos e reflexões que foram cruciais para ampliar e agenciar a análise dos dados produzidos. Nesse contexto, Creswell (2014, p. 50) afirma que "o relatório final ou apresentação incluem as vozes dos participantes, a reflexão do pesquisador, uma descrição complexa e interpretação do problema [...]”.

Após concluir que a "conversação é uma ferramenta indispensável para a comunicação entre os falantes e para que estes possam se posicionar de maneira crítica em seu próprio mundo" (MODESTO, 2011, p. 24), decidiu-se analisar as falas dos sujeitos da pesquisa adotando a técnica de análise da conversação, isso porque as manifestações dos pesquisados endereçavam também para esse fim, tendo em vista que os depoimentos dados sobre as potencialidades do Whatsapp começaram a ficar alinhados ao objetivo deste trabalho.

Este estudo buscou uma compreensão mais acirrada sobre a técnica de análise, compreendendo que na análise da conversação as averiguações, quase sempre, têm o propósito de explicar as estratégias e interações ocorridas entre os interlocutores, como também os mecanismos utilizados para que as necessidades de comunicação desses atores sejam efetivadas durante o processo interacional (MODESTO, 2011).

Em adesão ao pensamento do autor, explica-se que os elementos de conversação foram analisados na perspectiva de identificar as reais potencialidades do Whatsapp, no campo da investigação científica. Assim, as falas dos sujeitos pesquisados foram ouvidas, valorizadas e deram subsídios para interpretação e produção dos dados.

A partir da análise do material produzido, pode-se conceber o Whatsapp como uma rede social potencial também na pesquisa online, ainda que não seja o foco deste estudo. Isto pode ser verificado nas concepções dos estudantes extraídas do ambiente de pesquisa e posteriormente condensadas. Os eixos 'formação, tecnologia e currículo' foram identificados após análise das concepções, conforme Quadro 3. 
QUADRO 3 - Classificação dos dados em categorias de análise Grupo - Potencialidades do Whatsapp na formação profissional de docentes Classificação dos Dados em Categorias

\section{Concepções}

Os futuros docentes não se sentem preparados para trabalhar com as TDICs.

A realização de práticas inovadoras na universidade acrescenta nas práticas dos futuros docentes, o que refletirá na qualidade da educação básica.

$\mathrm{O}$ conhecimento e a prática que alguns estudantes têm são oriundos das experiências pessoais com o uso de mídias socais e com a internet.

Uma atualização contínua em inovações pedagógicas e tecnológicas pode romper com a prática estritamente tradicional.

Hoje em dia é praticamente inviável o docente pensar a aula utilizando basicamente o quadro de giz.

As TDICs na educação são facilitadoras do trabalho do docente e do estudante.

O uso das TDICs possibilita um ensino-aprendizagem inovador.

Os docentes são desafiados a encontrar novas metodologias de ensino para atender as novas situações que são apresentadas diante deles.

Abordar didaticamente as TDICs exige inovação, atualização e competência.

Muitos docentes têm restrição em utilizar as TDICs.

Os docentes necessitam apropriar-se pedagogicamente das ferramentas midiáticas.

As TDICs integram recursos educativos digitais que podem ser usados nas diversas áreas de conhecimento.

As redes sociais constituem espaços de interação, avaliação de aquisição de conhecimentos.

As TIDCs mudaram a forma de fazer educação e consequentemente as práticas dentro do contexto sala de aula.

As TDICs podem ser usadas concomitantemente às aulas e também no apoio de atividades de aprofundamento.

Não se podem negar as TDICs; tem-se que trazê-las para a sala de aula e fazer bom uso delas.

A partir das ferramentas disponíveis na internet, os docentes podem criar grupos para as suas disciplinas, o que facilitaria a troca de experiências e a solução de dúvidas sobre as aulas.

As TDICs consistem em uma perspectiva de mudança na forma de interação estudante-docente e pode aumentar o interesse do discente à aula.

A internet possibilita rapidez e produtividade para se informar e se comunicar de forma síncrona e assíncrona.

A EAD redimensiona os espaços de ensino e aprendizagem, do presencial ao virtual, ampliando o acesso de docentes e estudantes.

O Whatsapp representa um dos novos espaços que podem ser utilizados

\begin{tabular}{l|l|l|l|l|l|l} 
(C) ETD - Educ. Temat. Digit. & Campinas, SP & v.18 & n.1 & p. 104-121 & jan./abr.2016 & ISSN 1676-2592
\end{tabular}


para fins acadêmicos e didáticos.

O Facebook é um espaço que possibilita a criação de grupos, de páginas e de perfis.

É comum o uso do blog como portfólio online de uma disciplina, o que representa um meio interativo e colaborativo entre docente, conteúdo e discente.

O uso das TDICs na sala de aula potencializa as práticas docentes.

O ponto negativo das TDICs é a vulnerabilidade das barreiras técnicas.

O trabalho educativo descontextualizado do mundo dos estudantes pode ocasionar desinteresse e monotonia na sala de aula.

O currículo das licenciaturas nem sempre contempla matérias adequadas sobre a utilização pedagógica das TDICs.

Os cursos de Pedagogia geralmente ofertam uma única disciplina que aborda a integração das TDICs ao ensino.

O estudante deixa de tirar proveito do que as TDICs podem acrescentar em sua formação acadêmica e profissional.

Fonte: Produzido pelos autores

A partir da sintetização dos dados na tabela acima, é perceptível que embora os temas mais enfatizados pelos sujeitos-pesquisa tenham sido os compostos pela tríade: formação-tecnologiascurrículo; não se pode deixar de constatar a presença das TDICs em quase todas as falas. De uma forma ou de outra não se pode negar a presença das TDICs nas atividades acadêmicas que envolvem docentes e estudantes no contexto da educação superior. Isso sinaliza a necessidade de um processo contínuo de formação tanto dos docentes, que se utilizam dessas ferramentas para o desenvolvimento didático de suas aulas, quanto dos estudantes, que necessitam ter essas ferramentas expressas no currículo do seu cursos e no cotidiano da sala de aula.

\section{CONSIDERAÇÕES FINAIS}

Considerando os argumentos apresentados neste estudo, é de fundamental importância que o docente universitário compreenda o novo cenário educacional e se integre a um processo de formação contínua que concorra para o desenvolvimento das competências necessárias para um bom exercício profissional.

As formações continuadas do docente universitário deverão estar alicerçadas no desenvolvimento de dimensões que permitam repensar o papel e a função dos cursos de graduação no ensino superior - seu foco, sua finalidade, seus valores, que considerem os quatro grandes eixos desse processo: o próprio conceito de processo de ensino aprendizagem; o docente como conceptor e gestor do currículo; a compreensão da relação docente-estudante-estudante e estudante-estudante no processo; e a teoria e a prática básicas das TDICs (MASETTO, 1998).

Embora este estudo por meio do Whatsapp tenha analisado a formação profissional de docentes, presume-se que esse aplicativo como ferramenta tecnológica, se usado didaticamente, contribui para o desenvolvimento de atividades nos diversos campos de conhecimento. Além das 
mensagens, há a possibilidade de transmissão de áudio, compartilhamento de vídeos, músicas e imagens. Nesse sentido, uma proposta didática amparada por um projeto pedagógico com atividades que zelam pela utilização dessas mídias como objetos de análise e de autoria e coautoria, pode constituir em um meio potencial à construção colaborativa de saberes, principalmente na formação de estudantes que serão futuros docentes, que levarão legados como esse para o seu campo de atuação.

O Whatsapp não é mais um artefato tecnológico a ser utilizado de forma artificial por educadores sem profundidade conceptual e pedagógica, sem refletir criticamente sobre sua aplicação na educação. Uma ação pedagógica integrada às TDICs pode ser consistente e significativa, seja com o uso do Whatsapp ou de qualquer outro recurso midiático, quando essa ação vem revestida de um planejamento criterioso que justifique e enriqueça a conexão natural do conteúdo com a mídia, a partir de objetivos, metodologia e instrumentos avaliativos bem definidos.

\section{REFERÊNCIAS}

ALMEIDA, Maria Elizabeth Bianconcini de; MORAN, José Manuel. (Org.) Integração das tecnologias na educação. Brasília: MEC/SEED, 2005. Disponível em: <http://goo.gl/jw0RmF>. Acesso em: 25 jun. 2015.

ALSALEEM, Basma Issa Ahmad. The effect of "whatsAap" electronic dialogue journaling on improving writing vocabulary word choice and voice of EFL Undergraduate Saudi Students. AWEJ, v. 04, n. 03. 2013. Disponível em: < http://goo.gl/HrD0gq >. Acesso em: 25 jun. 2015. ISSN 22299327.

BASTOS, Maria Inês. O desenvolvimento de competências em "TIC para a Educação" na formação de docentes na América Latina. Brasília: MEC, 2010. Disponível em: < http://goo.gl/7ZNEcD $>$. Acesso em: 25 jun. 2015.

BARBOSA, Marily Oliveira; SANTOS, Arlete Rodrigues dos; MERCADO, Luís Paulo Leopoldo. Webginkana como estratégia de ensino aprendizagem no ensino superior. In: LOPES, Amélia, CAVAlCANTE, Maria Auxiliadora da Silva; OLIVEIRA, Dalila Andrade; HYPÓLITO, Álvaro Moreira. Trabalho docente e formação: políticas, práticas e investigação: pontes para a mudança. Porto: Edição: CIEE, 2014.

BRASIL. Portaria MEC n. 4.059/2004. Disponível em: < http://goo.g1/RHKwGc>. Acesso em: 30 jul. 2014.

CASTELLS, Manuel. A sociedade em rede: a era da informação: economia, sociedade e cultura. 10. ed. São Paulo: Paz e Terra, 2007. 
COSTA, Jivaneide Araújo Silva. A formação dos professores nos meios tecnológicos e midiáticos: um resgate da mídia áudio no ambiente escolar. In: MERCADO, Luís Paulo Leopoldo. (Org). Fundamentos e práticas na educação a distância. Maceió: EDUFAL, 2009. p.133-150.

COLL, César; MONEREO, Carles. Psicologia da educação virtual: aprender e ensinar com as tecnologias da informação e comunicação. Porto Alegre: Artmed, 2010.

CRESWELL, John. Projeto de pesquisa: métodos quantitativo, qualitativo e misto. 2. ed. Porto Alegre: Artmed, 2007.

CRESWELL, John. Investigação qualitativa e projeto de pesquisa: escolhendo entre cinco abordagens. 3. ed. Porto Alegre: Penso, 2014.

CUNHA, Maria Isabel. Reflexões e práticas em pedagogia universitária. Campinas, SP: Papirus, 2007.

FERNANDES, Daniela Gumiero; SANTOS, Rafael Felipe; SANTANA, Vanessa Fernandes.

Hábitos de consumo de música digital em multiplataformas. 2012. 54 f. Trabalho de Conclusão de Curso (Bacharel em Marketing) - Centro Universitário FAE, Curitiba, PR, 2012. Disponível em: < http://goo.gl/cxTXwR>. Acesso em: 07 jul. 2014.

FOGG, Piper. Professor: what to do when home is just another word for the office. Chronicle of Higher Education: B12, 2010.

FRAGOSO, Suely; RECUERO, Raquel; AMARAL, Adriana. Métodos de pesquisa para a internet. Porto Alegre: Sulina, 2012. 239 p.

IZZO, Margo Vreeburg; YURICK, Amanda, NAGARAJA, Haikady; NOVAK, Jeanne. Effects of a 21 st century curriculum on students' information technology and transition skills. Ohio: Lowa, 2010 .

KARSENTI, Thierry; VILLENEUVE, Sthéphane; RABY Carole. O uso pedagógico das tecnologias da informação e da comunicação na formação dos futuros docentes no Quebec. Educação \& Sociedade, Campinas, SP, v. 29, n. 104, p. 865-889. out./2008. Disponível em: < http://goo.gl/sNnwO4>. Acesso em: 25 jun. 2015. ISSN 1678-4626.

LENHART, Amanda; MADDEN, Mary; MACGILL, Alexandra; SMITH Aaron. Teens, social media \& technology overview 2015: smarthfones facilitate shifts in communication landscape for teens. 2007. Disponível em: < http://goo.gl/iSDPld>. Acesso: 19 jun. 2014.

MARINHO, Simão Pedro; LOBATO, Wolney. Tecnologias digitais na educação: desafios para a pesquisa na pós-graduação em educação. Anais eletrônicos. Colóquio de Pesquisa em Educação, 6, 2008, Belo Horizonte, MG. 2008. Disponível em: < http://goo.gl/ItxRD3>. Acesso em: 25 jun. 2015. 
MASETTO, Marcos. Docência na universidade. Campinas, SP: Papirus,1998.

MELO, Márcia Maria de Oliveira. Influências das crises da sociedade sobre o currículo e a docência universitária e as necessidades de rupturas epistemológicas e pedagógicas nessas práticas. In: MELO, Márcia Maria de Oliveira; CORDEIRO, Telma de Santa Clara. (Org.). Formação pedagógica e docência do professor universitário. Recife: UFPE, 2008.

MODESTO, Artaxerxes Tiago Tacito. Processos interacionais na Internet: análise da conversação digital. 2011. 196 f. Tese (Doutorado em Filologia e Língua Portuguesa) - Faculdade de Filosofia, Letras e Ciências Humanas, Universidade de São Paulo, São Paulo, SP, 2011. Disponível em: < http://goo.gl/dEJkNt>. Acesso em: 25 jun. 2015.

PALFREY, John. GASSER, Urs. Nascidos na era digital: entendendo a primeira geração de nativos digitais. Porto Alegre: Artmed, 2011.

PETERS, Otto. A educação a distância em transição: tendências e desafios. Porto Alegre: Unisinos, 2008.

RAMOS, Kátia. Reconfigurar a profissionalidade docente universitária: um olhar sobre ações de atualização pedagógico-didática. Porto: Universidade do Porto, 2010.

ROSSINI, Tatiana; SANTOS, Edméa. A mediação docente como interatividade: elementos essenciais para a educação na modalidade on-line em ambientes virtuais. Informática na Educação: Teoria \& Prática. Porto Alegre, RS, v. 16, n. 2. jul./dez. 2013. Disponível em:

< http://goo.gl/n14WjM $>$. Acesso em: 25 jun. 2015. ISSN 1982-1654.

SACRISTÁN, Gimeno. Consciência e ação sobre a prática como libertação profissional dos professores. In: NÓVOA, António (Org.) Profissão professor. 2. ed. Porto: Universidade do Porto, 1995.

SILVA, Marco. (Org.). Formação de professores para docência online. São Paulo: Loyola, 2012.

TARDIF, Maurice. Saberes docentes e formação profissional. 10. ed. Rio de Janeiro: Vozes, 2010.

UNIVERIDADE FEDERAL DE ALAGOAS. Projeto Político-Pedagógico do Curso de Pedagogia. Maceió, 2006.

UNIVERSIDADE FEDERAL DE VIÇOSA. Cibercult: Blog da disciplina Cibercultura/Jornalismo. Disponível em: 〈 http://goo.gl/3cDC1z〉. Acesso em: 30 jul. 2014. 
VALENTE, José Armando. Apropriação da tecnologia na escola: desafios e perspectivas. Vídeo. 6. Fórum Internacional de Educação/Região Metropolitana de Campinas - $1^{\circ}$ Fórum de Educação de Paulínia. Campinas, SP, 2011.

VALENTE, José Armando. Formação de educadores para uso da informática. Campinas, SP: NIED/UNICAMP, 2003.

VALENTE, José Armando. O computador na sociedade do conhecimento. Campinas, SP: UNICAMP, 1999.

VALENTE, José Armando. As tecnologias digitais e os diferentes letramentos. Pátio - Revista Pedagógica, Porto Alegre, RS, v. 11, n. 44, p. 12-15. jan. $/ 2008$.

ZABALZA, Miguel. O ensino universitário: seu cenário e seus protagonistas. Porto Alegre: Artmed, 2004.

\section{Como citar este documento:}

SANTOS, Vera Lucia Pontes dos; PEREIRA, Jasete Maria Santos; MERCADO, Luís Paulo Leopoldo. Whatsapp: um viés online como estratégia didática na formação profissional de docentes. ETD - Educação Temática Digital,

Campinas, SP, v. 18, n. 1, p. 104-121, abr. 2016. ISSN 1676-2592. Disponível em:

<http://periodicos.sbu.unicamp.br/ojs/index.php/etd/article/view/8637398>. Acesso em: 05 abr. 2016. doi: 〈http://dx.doi.org/10.20396/etd.v18i1.8637398>. 